\title{
Moderately Hypofractionated Intensity-modulated Radiotherapy With a Simultaneous Integrated Boost for Locally Advanced Head and Neck Cancer - Do Modern Techniques Fulfil Their Promise?
}

\author{
JÖRN WICHMANN ${ }^{1}$, MARTIN DURISIN $^{2}$, ROBERT MICHAEL HERMANN ${ }^{1,3}$, \\ ROLAND MERTEN $^{1}$ and HANS CHRISTIANSEN ${ }^{1}$ \\ ${ }^{1}$ Department of Radiotherapy, Hannover Medical School, Hannover, Germany; \\ ${ }^{2}$ Department of Otorhinolaryngology, Hannover Medical School, Hannover, Germany; \\ ${ }^{3}$ Center for Radiotherapy, Westerstede, Germany
}

\begin{abstract}
Background: Intensity-modulated radiotherapy (IMRT) with simultaneous integrated boost (SIB) and moderate hypofractionation offers an opportunity for defining individual doses and a reduction in overall treatment time in locally advanced head and neck cancer (HNSCC). We present retrospective data on toxicity and locoregional control of a patient cohort treated with an IMRT-SIB concept in comparison to normo-fractionated 3D-conformal radiotherapy (3D-RT). Patients and Methods: Between 2012 and 2014, 67 patients with HNSCC (stages III-IVB) were treated with IMRT-SIB either definitively or in the postoperative setting. These patients were matched with those of patients treated with normo-fractionated 3D-RT before mid-2012 and their clinical courses were compared. Chemotherapy or cetuximab was given concomitantly in both groups in the definitive situation (postoperatively, dependent on risk factors). Results: Significantly less toxicity was found in favor of IMRT-SIB concerning dysphagia, dermatitis, xerostomia, fibrosis, and lymphedema. After a median follow-up of 31 months (range=2-104 months), 3-year locoregional control was $73 \%$ for those treated with IMRT-SIB versus $78 \%$ for those treated with 3D-RT. Conclusion: This moderately hypofractionated IMRT-SIB concept was shown to be feasible, incurring less toxicity than conventional $3 D-R T$.
\end{abstract}

This article is freely accessible online.

Correspondence to: Jörn Wichmann, Department of Radiotherapy, Hannover Medical School, Carl-Neuberg-Str. 1, 30625 Hannover, Germany. Mobile: +49 17615322997, Fax: +49 5115329797, e-mail: wichmann.joern@mh-hannover.de

Key Words: Head and neck cancer, radiotherapy, IMRT, hypofractionation, toxicity.
In locally advanced head and neck cancer (HNSCC), radiotherapy (RT) is an essential element in curative treatment strategies, both in the definitive (in case of inoperability or to avoid mutilating surgery in oropharyngeal cancer) and in the postoperative adjuvant situation (1). Concomitant chemotherapy, usually cisplatinbased, improves the prognosis in the definitive (2), as well as in the postoperative adjuvant situation, especially in the case of extracapsular nodal spread (ECE) or microscopically involved resection margins (3).

Moderately hypofractionated RT has become more common in clinical practice. It is already the standard of care in postoperative adjuvant RT of breast cancer after breastconserving surgery (4) and is a guideline-based alternative in RT for prostate cancer $(5,6)$. Similarly, it has also already been used in HNSCC (7).

Currently, intensity modulated radiotherapy (IMRT) is used as the standard of care in RT for HNSCC to lower the risk of high-grade chronic toxicity (8). The implementation of IMRT also offers the possibility of utilizing simultaneous integrated boost (SIB) radiation for individual 'dose painting', i.e., defining different areas for target volumes which are treated with different doses in the same patient, and, using moderately hypofractionated concepts, for reduction of overall treatment time (9).

Here, we present a cohort of patients with locally advanced HNSCC treated in the curative setting with RT or radiochemotherapy, either definitively or postoperative adjuvantly, using a moderately hypofractionated IMRT-SIB concept implemented at our Institution. Data on toxicity and locoregional control (LRC) are reported and compared with a historical cohort of patients treated with normo-fractionated 3D conformal radiotherapy (3D-RT) before the IMRT era using a matched-pair analysis. 


\section{Patients and Methods}

From 2012 to 2014, the 67 patients with locally advanced cancer analyzed (stage III/IV without distant metastases; mostly with squamous cell carcinomas) were treated at our institution with RT with curative intent using the following moderately hypofractionated IMRT-SIB concepts. For definitive radiochemotherapy, we used a slightly modified fractionation as proposed by the Radiation Therapy Oncology Group 0022 trial: 66 Gy (daily dose=2.2 Gy) for gross tumor volumes, $62.4 \mathrm{~Gy}(2.08 \mathrm{~Gy})$ for elective cervical nodes considered to be at exceptionally high risk for subclinical disease, and $54 \mathrm{~Gy}(1.8 \mathrm{~Gy})$ for elective cervical nodes. In cases receiving postoperative adjuvant treatment, $62.4 \mathrm{~Gy}$ (daily dose=2.08 Gy) for the primary tumor region and cervical regions with involved nodes with ECE, 57.6 Gy (1.92 Gy) for cervical regions with involved nodes without ECE, and $54 \mathrm{~Gy}$ (1.8 Gy) for elective cervical nodes were given. All patients were immobilized with a thermoplastic mask, including the head, neck and shoulder regions. A planning computed tomographic scan with a minimum slice thickness of 3 $\mathrm{mm}$ was obtained for all patients. On each computed tomography slice, the gross tumor volumes were delineated by the treating physician, as well as the areas at especially high risk of potential microscopic disease and other potentially affected regions, including lymph nodes. The margins to compensate for setup variability and organ motions were generally $5 \mathrm{~mm}$. Furthermore, organs at risk such as the parotids, spinal cord, brachial plexus and brainstem, were drawn. All calculations were performed with Monaco ${ }^{\circledR}$ (Elekta $\mathrm{GmbH}$, Hamburg, Germany) by experienced physicists. A phantom measurement with PTW OCTAVIUS ${ }^{\circledR}$ (4D) Phantom (PTW Freiburg $\mathrm{GmbH}$, Freiburg, Germany) and the corresponding PTW VeriSoft ${ }^{\circledR}$ of the latest available version was performed to verify each plan. Planning objectives such as dose prescriptions and normal tissue constraints had to be realized according to International Commission on Radiation Units (ICRU) Report 83 (10) and to QUANTEC data (spinal cord Dmax <45 Gy, brachial plexus Dmax <54 Gy, contralateral parotid gland Dmean $<23$ Gy) (11). To reach these objectives/constraints, the planning target volume coverage was modified if necessary. For RT, linear accelerators with $6 \mathrm{MV}$ photon energy were used.

For comparison, another cohort was additionally analyzed using a matched-pair analysis. The 67 patients of this second cohort were treated before the IMRT era at our institution from 2008 to 2012 with normo-fractionated 3D-RT as follows: Primary and involved as well as elective cervical nodes received up to a dose of 50 Gy followed by a sequential boost to the primary and involved nodes (or regions with ECE in the case of adjuvant therapy) to a total dose of 70 (definitive) or 60 to 64 Gy (postoperative adjuvant). Planning was performed by multifield 3D conformal forward planning using 6,10 , and $15 \mathrm{MV}$ photon beams and a 'shrinking field approach'. Dose prescriptions were realized according to ICRU Report 50. To avoid long-term toxicity, the supraclavicular lymph nodes were mostly spared at 46 to $54 \mathrm{~Gy}$, and the spinal cord was spared at $45 \mathrm{~Gy}$.

For both cohorts, concomitant chemotherapy or cetuximab was given regularly in the definitive situation and in the postoperative adjuvant setting in cases with ECE or microscopically involved resection margins.

All patients were clinically assessed weekly during RT and 3 months later by experienced staff to evaluate and grade acute toxicity (oral mucositis, dysphagia, radiation dermatitis) according to Common Terminology Criteria for Adverse Events v4.03 (12).
Afterward, patients were asked to attend yearly follow-up visits to score late toxicities according to Late Effect in Normal Tissue classification (LENT)/SOMA (xerostomia, taste alteration, fibrosis, lymphedema, hoarseness, fistula, necrosis of mandible, and trismus) (13). Because some patients failed to show up at their regular appointments, we decided to report the worst observed toxicity during the follow-up, which has the most harmful consequence for the patients on its occurrence.

For this retrospective matched-pair analysis, approximately 200 consecutive patients who received and completed 3D-RT with curative intent for HNSCC between 01.2008 and 05.2012 were screened as controls. Furthermore, 67 consecutive patients who received hypofractionated IMRT-SIB between 06.2012 and 04.2014 were documented. To select patients treated with 3D-RT as controls, three variables had to match between the two groups: Sex, site of the primary tumor, and treatment concept (definitive versus postoperative). Demographic, histopathological, clinical, and toxicity data were collected retrospectively from the charts. Staging was performed according to the seventh version of the TNM Classification of Malignant Tumours (14).

After data collection, for comparison between the patient characteristics of both cohorts, the McNemar test for binary characteristics or Cohen's kappa for characteristics with more levels were used. LRC was analyzed using the Kaplan-Meier method (15). Differences in toxicity were tested for statistical significance with the Wilcoxon signed-rank test. We used SPSS version 26 (IBM, Armonk, NY, USA) to perform the statistical analyses. Significance was defined as $p<0.05$.

\section{Results}

Overall, in each group, 67 patients were analyzed (20 definitive, 47 postoperative in each). Median follow-up for the total study cohort was 31 months (range=3-104 months), with 37 months (range=3-104 months) for those treated with IMRT versus 29 months (range=3-94 months) for those treated with 3D-RT. The essential patient characteristics are summarized in Table I. They were sufficiently balanced between the groups. However, there were significantly more patients with ECE ( $27 \%$ versus $8 \%$ ) and treated with concomitant chemotherapy ( $70 \%$ versus $49 \%$ ) treated in the IMRT-SIB cohort, and six versus three patients suffered from $\mathrm{cN} 2 \mathrm{c}$ disease.

The worst acute and chronic toxicities observed during the follow-up are shown in Table II. There were no significant differences in the incidence of acute oral mucositis, although there were slightly more patients with at least grade 3 mucositis with 3D-RT (48\% versus $40 \%$ ). However, a statistically significant difference was documented, with lower toxicity in the IMRT-SIB group for overall dysphagia $(p=0.044)$ and radiation-induced dermatitis $(p=0.002)$.

Concerning late toxicity, xerostomia, fibrosis and edema were significantly lower in the IMRT-SIB group. Nine percent of patients treated with IMRT-SIB versus nearly $60 \%$ in the 3D-RT group suffered from grade $2 / 3$ xerostomia, $7.5 \%$ had grade $1 / 2$ fibrosis versus approximately $34 \%$, and grade $2 / 3$ edema was documented in $11.9 \%$ versus $44.8 \%$. 
Table I. Patient and tumor characteristics.

\begin{tabular}{|c|c|c|c|c|}
\hline Variable & Indicator & 3D-RT, n (\%) & IMRT-SIB, n (\%) & $p$-Value ${ }^{\#}$ \\
\hline \multirow[t]{2}{*}{ Gender } & Male & $53(79 \%)$ & $53(79 \%)$ & $>0.99$ \\
\hline & Female & $14(21 \%)$ & $14(21 \%)$ & \\
\hline \multirow[t]{6}{*}{ Tumor subsite } & Oral cavity & $24(36 \%)$ & $24(36 \%)$ & $\begin{array}{c}<\mathbf{0 . 0 0 5} \\
(\mathrm{K}=1.000)\end{array}$ \\
\hline & Oropharynx & $16(24 \%)$ & $16(24 \%)$ & \\
\hline & Hypopharynx & $6(9 \%)$ & $6(9 \%)$ & \\
\hline & Larynx & $8(12 \%)$ & $8(12 \%)$ & \\
\hline & Major salivary glands & $5(8 \%)$ & $5(8 \%)$ & \\
\hline & CUP & $8(12 \%)$ & $8(12 \%)$ & \\
\hline \multirow[t]{2}{*}{ Treatment concept } & Definitive & $20(30 \%)$ & $20(30 \%)$ & $>0.99$ \\
\hline & Adjuvant & $47(70 \%)$ & $47(70 \%)$ & \\
\hline \multirow[t]{2}{*}{ Age } & $<65$ Years & $47(70 \%)$ & $48(72 \%)$ & \\
\hline & $>65$ Years & $20(30 \%)$ & $19(28 \%)$ & \\
\hline \multirow[t]{2}{*}{ Histology } & SCC & $62(93 \%)$ & $59(88 \%)$ & $\begin{array}{c}\boldsymbol{p}<\mathbf{0 . 0 0 5} \\
(\mathrm{K}=0.423)\end{array}$ \\
\hline & Other & $5(7 \%)$ & $8(12 \%)$ & \\
\hline \multirow[t]{5}{*}{ Grade } & 1 & $0(0 \%)$ & $2(3 \%)$ & \\
\hline & 2 & $39(58 \%)$ & $35(52 \%)$ & $\begin{array}{c}0.619 \\
(\mathrm{~K}=-0.058)\end{array}$ \\
\hline & 3 & $27(40 \%)$ & $26(39 \%)$ & \\
\hline & 4 & $0(0 \%)$ & $1(2 \%)$ & \\
\hline & $\mathrm{X}$ & $1(2 \%)$ & $3(5 \%)$ & \\
\hline \multirow[t]{3}{*}{ UICC stage } & III & $16(24 \%)$ & $15(22 \%)$ & $\begin{array}{c}<\mathbf{0 . 0 0 5} \\
(\mathrm{K}=0.579)\end{array}$ \\
\hline & IVA & $47(70 \%)$ & $46(69 \%)$ & \\
\hline & IVB & $4(6 \%)$ & $4(6 \%)$ & \\
\hline \multirow[t]{4}{*}{ Resection status } & R0 & $34(51 \%)$ & $39(58 \%)$ & $\begin{array}{c}<\mathbf{0 . 0 0 5} \\
(\mathrm{K}=0.614)\end{array}$ \\
\hline & $\mathrm{R} 1$ & $6(9 \%)$ & $4(6 \%)$ & \\
\hline & $\mathrm{R} 2$ & $0(0 \%)$ & $1(2 \%)$ & \\
\hline & $\mathrm{RX}$ & $5(8 \%)$ & $3(5 \%)$ & \\
\hline \multirow[t]{2}{*}{ Treatment for relapse $\mathrm{e}^{\dagger}$} & Yes & $12(18 \%)$ & $6(9 \%)$ & 0.210 \\
\hline & No & $55(82 \%)$ & $61(91 \%)$ & \\
\hline \multirow[t]{3}{*}{ ECE } & Yes & $5(8 \%)$ & $18(27 \%)$ & 0.001 \\
\hline & No & $47(70 \%)$ & $29(43 \%)$ & \\
\hline & Not examined & $15(22 \%)$ & $20(30 \%)$ & \\
\hline \multirow{2}{*}{ Chemotherapy } & Yes & $33(49 \%)$ & $47(70 \%)$ & 0.007 \\
\hline & No & $34(51 \%)$ & $20(30 \%)$ & \\
\hline
\end{tabular}

$\dagger$ The current treatment was due to a relapse. \#McNemar or Cohen's kappa test with kappa value in parentheses. Cohen's kappa: <0.00 poor, 0.00 0.20 slight, 0.21-0.40 fair, 0.41-0.60 moderate, 0.61-0.80 substantial, and 0.81-1.00 almost perfect agreement according to (34); negative Cohen's kappa cannot be interpreted, therefore there is no statistical significance. Statistically significant differences are shown in bold.

Three-year LRC was $73 \%$ under SIB-IMRT versus $78 \%$ under 3D-RT and median LRC was not reached versus 69.5 months, respectively (log-rank chi-square $=0.143, p=0.705$; Figure 1).

\section{Discussion}

With the advent of IMRT in RT for HNSCC as a standard of care, diverse individual concepts have been implemented in different RT departments. The application of SIB and moderate hypofractionation are often applied to ensure individual dose painting and reduction of overall treatment time, which is crucial in RT for HNSCC (16).

To our knowledge, there is little prospective randomized evidence evaluating the efficacy of IMRT in comparison to 3D-RT in the RT of HNSCC. One study (PASPORT) randomized 94 patients between IMRT and 3D-RT (with parallel opposed lateral fields) (17). This study was focused on avoiding xerostomia. At 12 and 24 months, xerostomia of at least grade 2 was significantly less prevalent after IMRT. Other late toxicities, LRC and overall survival did not differ between the groups. Comparable results were 
Table II. Acute and late toxicity according to Common Terminology Criteria for Adverse Events (12) and Late Effect in Normal Tissue - Subjective, Objective, Management, Analytic (LENT-SOMA) classification (13) reported as the worst observed during the follow-up.

\begin{tabular}{|c|c|c|c|c|c|c|}
\hline \multirow[b]{2}{*}{ Acute } & \multirow{2}{*}{$\begin{array}{c}\text { Toxicity } \\
\text { Mucositis }\end{array}$} & \multirow{2}{*}{$\frac{\text { Grade }}{0}$} & \multirow{2}{*}{$\frac{\text { IMRT group }}{1(1.5 \%)}$} & \multirow{2}{*}{$\begin{array}{c}\text { Control group } \\
0\end{array}$} & \multicolumn{2}{|c|}{ Statistical analysis } \\
\hline & & & & & Z-Value (Wilcoxon) & -0.688 \\
\hline & & I & $6(9.0 \%)$ & $7(10.4 \%)$ & $p$-Value & 0.492 \\
\hline & & II & $33(49.3 \%)$ & $28(41.8 \%)$ & Matched, $n$ & 67 \\
\hline & & III & $27(40.3 \%)$ & $32(47.8 \%)$ & $\mathrm{r}$ & 0.08 \\
\hline & & IV & 0 & 0 & Effect & NS \\
\hline & & Median & 2 & 2 & & \\
\hline & Dermatitis & 0 & $1(1.5 \%)$ & 0 & Z-Value (Wilcoxon) & -3.024 \\
\hline & & I & $49(73.1 \%)$ & $40(59.7 \%)$ & $p$-Value & 0.002 \\
\hline & & II & $17(25.4 \%)$ & $22(32.8 \%)$ & Matched, $\mathrm{n}$ & 67 \\
\hline & & III & 0 & $5(7.5 \%)$ & $\mathrm{r}$ & 0.37 \\
\hline & & IV & 0 & 0 & Effect & Significant, medium \\
\hline & & Median & 1 & 1 & & \\
\hline & Dysphagia & 0 & $9(13.4 \%)$ & $1(1.5 \%)$ & Z-Value (Wilcoxon) & -2.014 \\
\hline & & I & $9(13.4 \%)$ & $6(9.0 \%)$ & $p$-Value & 0.044 \\
\hline & & II & $20(29.9 \%)$ & $28(41.8 \%)$ & Matched, $\mathrm{n}$ & 66 \\
\hline & & III & $28(41.8 \%)$ & $32(47.8 \%)$ & $\mathrm{r}$ & 0.25 \\
\hline & & IV & 0 & 0 & Effect & Significant, medium \\
\hline & & Median & 2 & 2 & & \\
\hline \multirow[t]{39}{*}{ Late } & Xerostomia & 0 & $3(4.5)$ & $4(6.0 \%)$ & Z-Value (Wilcoxon) & -4.029 \\
\hline & & I & $43(64.2 \%)$ & $10(14.9 \%)$ & $p$-Value & $<0.0001$ \\
\hline & & II & $6(9.0 \%)$ & $32(47.8 \%)$ & Matched, $\mathrm{n}$ & 45 \\
\hline & & III & 0 & $8(11.9 \%)$ & $\mathrm{r}$ & 0.60 \\
\hline & & IV & 0 & 0 & Effect & Significant, large \\
\hline & & Median & 1 & 2 & & \\
\hline & Fibrosis & 0 & $47(70.1 \%)$ & $31(46.3 \%)$ & Z-Value (Wilcoxon) & -3.554 \\
\hline & & I & $5(7.5 \%)$ & $18(26.9 \%)$ & $p$-Value & $<0.0001$ \\
\hline & & II & 0 & $5(7.5 \%)$ & Matched, $\mathrm{n}$ & 45 \\
\hline & & III & 0 & 0 & r & 0.53 \\
\hline & & IV & 0 & 0 & Effect & Significant, large \\
\hline & & Median & 0 & 0 & & \\
\hline & Hoarseness & 0 & $34(50.7 \%)$ & $38(56.7 \%)$ & Z-Value (Wilcoxon) & -0.220 \\
\hline & & I & $15(22.4 \%)$ & $9(13.4 \%)$ & $p$-Value & 0.826 \\
\hline & & II & 0 & $6(9.0 \%)$ & Matched, n & 44 \\
\hline & & III & $1(1.5 \%)$ & $1(1.5 \%)$ & $\mathrm{r}$ & 0.03 \\
\hline & & IV & 0 & 0 & & Effect NS \\
\hline & & Median & 0 & 0 & & \\
\hline & Taste alteration & 0 & $20(29.9 \%)$ & $22(32.8 \%)$ & Z-Value (Wilcoxon) & -1.136 \\
\hline & & I & $28(41.8 \%)$ & $20(29.9 \%)$ & $p$-Value & 0.256 \\
\hline & & II & $4(6.0 \%)$ & $12(17.9 \%)$ & Matched, $\mathrm{n}$ & 45 \\
\hline & & III & 0 & 0 & $\mathrm{r}$ & 0.17 \\
\hline & & IV & 0 & 0 & Effect & NS \\
\hline & & Median & 1 & 1 & & \\
\hline & Edema & 0 & $28(41.8 \%)$ & $14(20.9 \%)$ & Z-Value (Wilcoxon) & -3.749 \\
\hline & & I & $16(23.9 \%)$ & $10(14.9 \%)$ & $p$-Value & $<0.0001$ \\
\hline & & II & $7(10.4 \%)$ & $29(43.3 \%)$ & Matched, $\mathrm{n}$ & 45 \\
\hline & & III & $1(1.5 \%)$ & $1(1.5 \%)$ & $\mathrm{r}$ & 0.56 \\
\hline & & IV & 0 & & Effect & Significant, large \\
\hline & & Median & 0 & 2 & & \\
\hline & Trismus & 0 & $51(76.1 \%)$ & $49(73.1 \%)$ & Z-Value (Wilcoxon) & -1.134 \\
\hline & & I & 0 & $3(4.5 \%)$ & $p$-Value & 0.257 \\
\hline & & II & $1(1.5 \%)$ & $2(3.0 \%)$ & Matched, n & 45 \\
\hline & & III & 0 & 0 & r & 0.17 \\
\hline & & IV & 0 & 0 & Effect & NS \\
\hline & & Median & 0 & 0 & & \\
\hline & Necrosis & 0 & $50(74.6 \%)$ & $49(73.1 \%)$ & Z-Value (Wilcoxon) & -1.687 \\
\hline & & I & 0 & $1(1.5 \%)$ & $p$-Value & 0.092 \\
\hline & & II & $1(1.5 \%)$ & $1(1.5 \%)$ & Matched, $\mathrm{n}$ & 45 \\
\hline
\end{tabular}


Table II. Continued

\begin{tabular}{|c|c|c|c|c|c|}
\hline Toxicity & Grade & IMRT group & Control group & \multicolumn{2}{|c|}{ Statistical analysis } \\
\hline \multirow{9}{*}{ Fistula } & III & $1(1.5 \%)$ & $1(1.5 \%)$ & $r$ & 0.25 \\
\hline & IV & 0 & $2(3.0 \%)$ & Effect & NS \\
\hline & Median & 0 & 0 & & \\
\hline & 0 & $51(76.1 \%)$ & $53(79.1 \%)$ & Z-Value (Wilcoxon) & -0.447 \\
\hline & I & 0 & 0 & $p$-Value & 0.655 \\
\hline & II & 0 & 0 & Matched, $\mathrm{n}$ & 45 \\
\hline & III & 0 & $1(1.5 \%)$ & $\mathrm{r}$ & 0.07 \\
\hline & IV & $1(1.5 \%)$ & 0 & Effect & NS \\
\hline & Median & 0 & 0 & & \\
\hline
\end{tabular}

$\mathrm{N}$ : Number of pairs both of which reported adverse events; NS: non-significant. r: Effect size, calculated as $r=Z /(\sqrt{ } N)$. Effect: $r<0.3$ : small effect, $\mathrm{r}$ between 0.3 and 0.5: medium effect, r $>0.5$ : large effect according to Cohen.

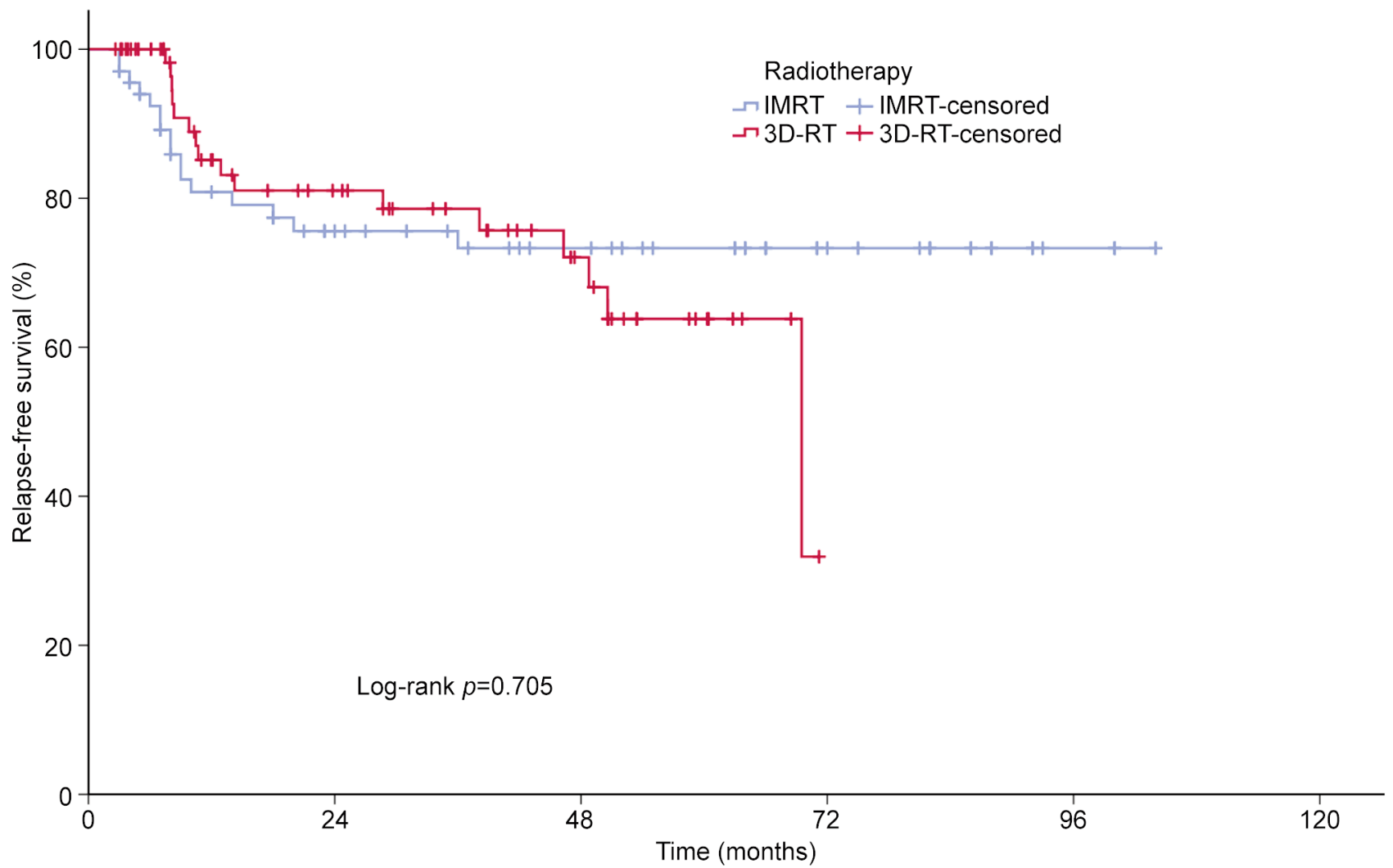

Figure 1. Relapse-free survival in study patients.

obtained in a small randomized trial ( $\mathrm{n}=60$ patients) from India (18).

In nasopharyngeal cancer, this advanced technique demonstrated a higher oncological efficacy in 616 patients compared to outdated 2D planning techniques: Overall and progression-free survival were significantly improved. At the same time, high-grade chronic toxicity was reduced (19).
The recently published GORTEC 2004-01 randomized phase III trial again showed that the IMRT technique can even reach a dose escalation with markedly decreased late xerostomia, but without a significant improvement of local tumor control (20). The authors used a slightly different irradiation concept with a sequential moderate hypofractionated boost to 75 Gy overall dose (25 Gy/10 fractions boost dose) in a total of 35 fractions. The frequency 
of grade 2 or more xerostomia was approximately two-thirds lower after 1 and 3 years in the IMRT-treated group.

Finally, Gupta et al. repeatedly showed in a prospective randomized trial with a very long follow-up and sufficient power and sample size that moderate hypofractionation with 66 Gy in 30 fractions and the IMRT technique led to a meaningful reduction in severe xerostomia and fibrosis with comparable LRC and overall survival in the 3D control group (21).

Other observational studies support the finding of lower acute and chronic toxicity by IMRT in RT for HNSCC in comparison to 3D planning. In this context, Jirkovska et al. demonstrated that acute toxicity and xerostomia were significantly reduced in HNSCC treated by IMRT (22). Modesto et al. showed similar data, especially for severe late toxicities such as xerostomia, dysphagia, and feeding-tube dependency (23). Our data confirm these findings, showing lower toxicity in the IMRT-SIB group for dysphagia, dermatitis, xerostomia, fibrosis, and edema.

Other retrospective studies also showed an advantage for IMRT concerning prognosis in LRC (24) or even overall survival (25). In contrast, in our patients, LRC was equal for the two groups. Despite the matched pair analysis, other biases due to the study's retrospective nature might play a role. However, such a finding is not totally in conflict with the literature. A recent meta-analysis on IMRT versus 3D-RT in RT for HNSCC confirmed the superiority of IMRT in terms of toxicity (mainly xerostomia) but did not find improved oncological outcomes. The authors concluded that a positive impact of IMRT on tumor control (and survival) remains to be proven (8).

Nowadays the immune microenvironment, especially persistent human papillomavirus (HPV) infection as a risk factor for the development of oropharyngeal squamous cell carcinoma, is playing a growing role as a prognostic factor and basis for therapeutic decisions. Recent de-escalation studies show partly encouraging results and the IMRT technique, as well as SIB concepts might be helpful tools in this situation (26). IMRT-SIB RT concepts therefore might further be modified according to HPV status in locally advanced HNSCC. On the one hand, patients with HPVpositive tumors have a better prognosis and are possible candidates for dose reduction, which is the subject of several ongoing clinical trials [reviewed in (27)]. On the other hand, other studies have examined the feasibility of dose-escalated hypofractionated chemoradiation in HPV-negative cancer (28). Unfortunately, in our retrospective patient cohorts, HPV status was not available for most of the tumors.

As concomitant chemotherapy in RT for locally advanced HNSCC is crucial for prognosis in definitive and specific postoperative adjuvant situations, RT approaches must be designed so that the dose and fractionation concepts do not compromise the use of concurrent systemic therapy and vice versa. Therefore, we chose mostly a chemotherapy protocol with weekly low-dose cisplatin $\left(40 \mathrm{mg} / \mathrm{m}^{2}\right.$ up to cumulative dose to at least $200 \mathrm{mg} / \mathrm{m}^{2}$ ) as a continuous radiosensitizer and decided against a higher hypofractionated RT schedule with more than 2.2 Gy to the target volume. Such a low-dose weekly application of cisplatin is an established regimen (29) in addition to the often used high-dose application, for example, $100 \mathrm{mg} / \mathrm{m}^{2}$ twice or thrice during RT (3). A cumulative cisplatin dose of approximately $200 \mathrm{mg} / \mathrm{m}^{2}$, independent of the schedule, might be sufficient to yield a beneficial antitumor effect (30). However, prospective studies in adequately sized phase III trials on this subject are still pending (31). We observed good tolerance and feasibility of our approach with moderate hypofractionation without compromising one part of the combined treatment. Other studies actually show that higher hypofractionation (with single doses in SIB volumes up to 2.25 or $2.4 \mathrm{~Gy}$ ) combined with chemotherapy seems to be possible $(32,33)$.

In summary, the presented moderately hypofractionated IMRT-SIB concept was feasible with acceptable LRC and less toxicity than conventional 3D-RT. IMRT is the standard of care in RT for locally advanced HNSCC. The optimal dose/fractionation concept concerning moderate hypofractionation still has to be defined.

\section{Conflicts of Interest}

The Authors declare no conflict of interest. The study was conducted according to the guidelines of the Declaration of Helsinki, and approved by the Institutional Ethics Committee of Hannover Medical School (protocol code 1795-2013).

\section{Authors' Contributions}

Conceptualization, JW and $\mathrm{CH}$; methodology, JW and $\mathrm{CH}$; software, JW; formal analysis, JW; writing-original draft preparation, JW, RM H, CH; writing-review and editing, MD and RM. All Authors have read and agreed to the published version of the article.

\section{Acknowledgements}

The Authors would like to thank Loukia Spineli for her assistance with the analysis plan at the earlier stages of the study.

\section{References}

1 Marur S and Forastiere AA: Head and neck squamous cell carcinoma: Update on epidemiology, diagnosis, and treatment. Mayo Clin Proc 91(3): 386-396, 2016. PMID: 26944243. DOI: 10.1016/j.mayocp.2015.12.017

2 Pignon JP, le Maître A, Maillard E, Bourhis J and MACH-NC Collaborative Group: Meta-analysis of chemotherapy in head and neck cancer (MACH-NC): an update on 93 randomised trials and 17,346 patients. Radiother Oncol 92(1): 4-14, 2009. PMID: 19446902. DOI: 10.1016/j.radonc.2009.04.014 
3 Bernier J, Cooper JS, Pajak TF, van Glabbeke M, Bourhis J, Forastiere A, Ozsahin EM, Jacobs JR, Jassem J, Ang KK and Lefèbvre JL: Defining risk levels in locally advanced head and neck cancers: a comparative analysis of concurrent postoperative radiation plus chemotherapy trials of the EORTC (\#22931) and RTOG (\#9501). Head Neck 27(10): 843-850, 2005. PMID: 16161069. DOI: $10.1002 /$ hed 20279

4 Interdisziplinäre S3-Leitlinie für die Früherkennung, Diagnostik, Therapie und Nachsorge des Mammakarzinoms. Langversion 4.3 - Februar 2020. AWMF-Registernummer: 032-045OL. Available at: https://www.leitlinienprogramm-onkologie.de/fileadmin/user_ upload/Downloads/Leitlinien/Mammakarzinom_4_0/Version_4.3 /LL_Mammakarzinom_Langversion_4.3.pdf. [Last accessed on May $4^{\text {th }}, 2021$ ]

5 Interdisziplinäre Leitlinie der Qualität S3 zur Früherkennung, Diagnose und Therapie der verschiedenen Stadien des Prostatakarzinoms. Version 5.1 - Mai 2019 AWMFRegisternummer: 043/022OL. Available at: https:// www.leitlinienprogramm-onkologie.de/fileadmin/user_upload/ Downloads/Leitlinien/Prostata_5_0/LL_Prostatakarzinom_Langv ersion_5.1.pdf. [Last accessed on May $4^{\text {th }}, 2021$ ]

6 Vassis S, Nöldeke B, Christiansen H, von Klot CA and Merten R: Moderately HRT vs. CRT for localized prostate cancer using image-guided VMAT with SIB: evaluation of acute and late toxicities. Strahlenther Onkol 196(7): 598-607, 2020. PMID: 32040691. DOI: 10.1007/s00066-020-01589-w

7 Franzese C, Fogliata A, Franceschini D, Navarria P, Cozzi L, Tomatis S, De Virgilio A, Spriano G and Scorsetti M: Impact of hypofractionated schemes in radiotherapy for locally advanced head and neck cancer patients. Laryngoscope 130(4): E163E170, 2020. PMID: 31063588. DOI: 10.1002/lary.28048

8 DE Felice F, Pranno N, Papi P, Brugnoletti O, Tombolini V and Polimeni A: Xerostomia and clinical outcomes in definitive intensity modulated radiotherapy (IMRT) versus threedimensional conformal radiotherapy (3D-CRT) for head and neck squamous cell carcinoma: A meta-analysis. In Vivo 34(2): 623-629, 2020. PMID: 32111762. DOI: 10.21873/invivo.11816

9 Orlandi E, Palazzi M, Pignoli E, Fallai C, Giostra A and Olmi $\mathrm{P}$ : Radiobiological basis and clinical results of the simultaneous integrated boost (SIB) in intensity modulated radiotherapy (IMRT) for head and neck cancer: A review. Crit Rev Oncol Hematol 73(2): 111-125, 2010. PMID: 19409808. DOI: 10.1016/j.critrevonc.2009.03.003

10 ICRU Report 83: Prescribing, recording, and reporting photonbeam intensity-modulated radiation therapy (IMRT). J ICRU 10(1): Report 83, 2010. DOI: 10.1093/jicru/10.1.Report83

11 Bentzen SM, Constine LS, Deasy JO, Eisbruch A, Jackson A, Marks LB, Ten Haken RK and Yorke ED: Quantitative Analyses of Normal Tissue Effects in the Clinic (QUANTEC): an introduction to the scientific issues. Int J Radiat Oncol Biol Phys 76(3 Suppl): S3-S9, 2010. PMID: 20171515. DOI: 10.1016/ j.ijrobp.2009.09.040

12 NCI Common Terminology Criteria for Adverse Events (CTCAE). Available at: https://evs.nci.nih.gov/ftp1/CTCAE/ About.html. [Last accessed on March 1st, 2021]

13 Lent Soma tables. Radiother Oncol 35(1): 17-60, 1995. PMID: 7569012.

14 Sobin LH, Gospodarowicz MK and Wittekind C (eds.): TNM Classification of Malignant Tumours, Seventh Edition. WileyBlackwell, 2011.
15 Kaplan E and Meier P: Nonparametric estimation from incomplete observations. J Am Stat Assoc 58: 457-481, 1958. DOI: $10.2307 / 2281868$

16 Dahlke S, Steinmann D, Christiansen H, Durisin M, Eckardt A, Wegener G, Bremer M and Meyer A: Impact of time factors on outcome in patients with head and neck cancer treated with definitive radio(chemo)therapy. In Vivo 31(5): 949-955, 2017. PMID: 28882964. DOI: 10.21873/invivo.11152

17 Nutting CM, Morden JP, Harrington KJ, Urbano TG, Bhide SA, Clark C, Miles EA, Miah AB, Newbold K, Tanay M, Adab F, Jefferies SJ, Scrase C, Yap BK, A'Hern RP, Sydenham MA, Emson M, Hall E and PARSPORT trial management group: Parotid-sparing intensity modulated versus conventional radiotherapy in head and neck cancer (PARSPORT): a phase 3 multicentre randomised controlled trial. Lancet Oncol 12(2): 127-136, 2011. PMID: 21236730. DOI: 10.1016/S14702045(10)70290-4

18 Ghosh-Laskar S, Yathiraj PH, Dutta D, Rangarajan V, Purandare N, Gupta T, Budrukkar A, Murthy V, Kannan S and Agarwal JP: Prospective randomized controlled trial to compare 3dimensional conformal radiotherapy to intensity-modulated radiotherapy in head and neck squamous cell carcinoma: Longterm results. Head Neck 38 Suppl 1: E1481-E1487, 2016. PMID: 26561342. DOI: 10.1002/hed.24263

19 Peng G, Wang T, Yang KY, Zhang S, Zhang T, Li Q, Han J and Wu G: A prospective, randomized study comparing outcomes and toxicities of intensity-modulated radiotherapy $v s$. conventional two-dimensional radiotherapy for the treatment of nasopharyngeal carcinoma. Radiother Oncol 104(3): 286293, 2012. PMID: 22995588. DOI: 10.1016/j.radonc.2012. 08.013

20 Tao Y, Auperin A, Blanchard P, Alfonsi M, Sun XS, Rives M, Pointreau Y, Castelli J, Graff P, Wong Hee Kam S, Thariat J, Veresezan O, Heymann S, Renard-Oldrini S, Lafond C, Cornely A, Casiraghi O, Boisselier P, Lapeyre M, Biau J and Bourhis J: Concurrent cisplatin and dose escalation with intensitymodulated radiotherapy (IMRT) versus conventional radiotherapy for locally advanced head and neck squamous cell carcinomas (HNSCC): GORTEC 2004-01 randomized phase III trial. Radiother Oncol 150: 18-25, 2020. PMID: 32417348. DOI: 10.1016/j.radonc.2020.05.021

21 Gupta T, Sinha S, Ghosh-Laskar S, Budrukkar A, Mummudi N, Swain M, Phurailatpam R, Prabhash K and Agarwal JP: Intensity-modulated radiation therapy versus three-dimensional conformal radiotherapy in head and neck squamous cell carcinoma: long-term and mature outcomes of a prospective randomized trial. Radiat Oncol 15(1): 218, 2020. PMID: 32938468. DOI: 10.1186/s13014-020-01666-5

22 Jirkovska M, Novak T, Malinova B and Lohynska R: Threedimensional conformal radiotherapy versus intensity modulated radiotherapy with simultaneous integrated boost in the treatment of locally advanced head and neck carcinoma. Neoplasma 66(5): 830-838, 2019. PMID: 31288530. DOI: 10.4149/neo_2018_ 181209 N941

23 Modesto A, Laprie A, Vieillevigne L, Graff P, Sarini J, Vergez S, Delord JP, Farenc JC, Vigarios E, Filleron T and Rives M: Intensity-modulated radiotherapy for laryngeal and hypopharyngeal cancer: minimization of late dysphagia without jeopardizing tumor control. Strahlenther Onkol 191(3): 225-233, 2015. PMID: 25367098. DOI: 10.1007/s00066-014-0767-1 
24 Mok G, Gauthier I, Jiang H, Huang SH, Chan K, Witterick IJ, O'Sullivan B, Waldron JN, Bayley AJ, Cho BC, Cummings BJ, Dawson LA, Hope AJ, Kim JJ and Ringash J: Outcomes of intensity-modulated radiotherapy versus conventional radiotherapy for hypopharyngeal cancer. Head Neck 37(5): 655661, 2015. PMID: 24590756. DOI: 10.1002/hed.23649

25 Kılıç S, Kılıç SS, Hsueh WD, Eloy JA, Baredes S, Woo Park RC and Mahmoud O: Radiotherapy modality as a predictor of survival in hypopharyngeal cancer. Head Neck 40(11): 24412448, 2018. PMID: 30306665. DOI: 10.1002/hed.25360

26 Adelstein DJ, Ismaila N, Ku JA, Burtness B, Swiecicki PL, Mell L, Beitler JJ, Gross N, Jones CU, Kaufman M, Le QT, Semrad TJ, Siu LL and Ridge JA: Role of treatment deintensification in the management of p16+ oropharyngeal cancer: ASCO provisional clinical opinion. J Clin Oncol 37(18): 1578-1589, 2019. PMID: 31021656. DOI: 10.1200/JCO.19.00441

27 Patel RR, Ludmir EB, Augustyn A, Zaorsky NG, Lehrer EJ, Ryali R, Trifiletti DM, Adeberg S, Amini A and Verma V: Deintensification of therapy in human papillomavirus associated oropharyngeal cancer: A systematic review of prospective trials. Oral Oncol 103: 104608, 2020. PMID: 32163853. DOI: 10.1016/ j.oraloncology.2020.104608

28 Meade S, Gaunt P, Hartley A, Robinson M, Harrop V, Cashmore J, Wagstaff L, Babrah J, Bowden SJ, Mehanna H and Sanghera P: Feasibility of dose-escalated hypofractionated chemoradiation in human papilloma virus-negative or smoking-associated oropharyngeal cancer. Clin Oncol (R Coll Radiol) 30(6): 366374, 2018. PMID: 29478732. DOI: 10.1016/j.clon.2018.01.015

29 Weykamp F, Seidensaal K, Rieken S, Green K, Mende S, Zaoui K, Freier K, Adeberg S, Debus J and Welte SE: Age-dependent hemato- and nephrotoxicity in patients with head and neck cancer receiving chemoradiotherapy with weekly cisplatin. Strahlenther Onkol 196(6): 515-521, 2020. PMID: 31784802. DOI: $10.1007 / \mathrm{s} 00066-019-01550-6$
30 Ang KK: Concurrent radiation chemotherapy for locally advanced head and neck carcinoma: are we addressing burning subjects? J Clin Oncol 22(23): 4657-4659, 2004. PMID: 15534361. DOI: $10.1200 / \mathrm{JCO} .2004 .07 .962$

31 Szturz P, Wouters K, Kiyota N, Tahara M, Prabhash K, Noronha V, Castro A, Licitra L, Adelstein D and Vermorken JB: Weekly low-dose versus three-weekly high-dose cisplatin for concurrent chemoradiation in locoregionally advanced non-nasopharyngeal head and neck cancer: a systematic review and meta-analysis of aggregate data. Oncologist 22(9): 1056-1066, 2017. PMID: 28533474. DOI: 10.1634/theoncologist.2017-0015

32 Guerrero Urbano T, Clark CH, Hansen VN, Adams EJ, A'Hern $\mathrm{R}$, Miles EA, McNair H, Bidmead M, Warrington AP, Dearnaley DP, Harrington KJ and Nutting CM: A phase I study of doseescalated chemoradiation with accelerated intensity modulated radiotherapy in locally advanced head and neck cancer. Radiother Oncol 85(1): 36-41, 2007. PMID: 17709149. DOI: 10.1016/j.radonc.2007.07.011

33 Schwartz M, Vuong T, Ballivy O, Parker W and Patrocinio H: Accelerated radiotherapy with simultaneous integrated boost fractionation and intensity-modulated radiotherapy for advanced head and neck cancer. Otolaryngol Head Neck Surg 136(4): 549555, 2007. PMID: 17418249. DOI: 10.1016/j.otohns.2006. 10.044

34 Landis JR and Koch GG: The measurement of observer agreement for categorical data. Biometrics 33(1): 159-174, 1977. PMID: 843571. 